\title{
Non-incremental shuttle-avoidance acquisition to pressurized air US'
}

\author{
A. JOSEPH RAY, JR. ${ }^{2}$ \\ NORTH DAKOTA STATE UNIVERSITY
}

Forty-nine healthy, experimentally naive rats of the SpragueDawley strain were trained in a shuttle-avoidance apparatus to a pressurized air US with either an $11 \mathrm{sec}$. CS-IIS interval (group I, $\mathrm{N}=28$ ) or an $8 \mathrm{sec}$. CS-US interval (group II, $\mathrm{N}=$ 21) and a $2 \frac{1}{2} \mathrm{~min}$. intertrial interval. CS was a 65 decibel buzzer. No significant difference in rate or nature of learning between groups was found, and they were therefore combined. Forty-five rats acquired the avoidance response to a criterion of five avoidances in six trials in a mean of 9.22 trials (s.e. $=1.00$ trial). Acquisition was non-incremental: subjects shifted abruptly from escape responding to avoidance responding ( $p<.01)$ without oscillating. The data are contrasted with results from electric shock shuttle-avoidance where learning has been seen repeatedly to be incremental in nature. Results are interpreted as sustaining a one-trial learning hypothesis in shuttle-avoidance acquisition.

Prevailing opinion concerning shuttle-avoidance learning holds that acquisition in this situation is a gradual, incremental process. Atkinson, Bower, \& Crothers (1965) state that shuttle-avoidance, unlike one-way avoidance, is characterized both by a slow rate of acquisition and a high degree of oscillation between conditioned and unconditioned responses before the avoidance habit is fully learned.

These and other writers (Theios \& Dunaway, 1964; Baum, 1965) have not considered the proposition that the slow rate of learning and excessive oscillation observed in shuttle-avoidance may be due, not to the internal complexities of the shuttle task (the usual explanation: see Atkinson et al, 1965; Baum, 1965), but rather to undesirable emotional excitement induced by electric shock-the unconditioned stimulus commonly utilized in shuttle-avoidance experiments. That electric shock sufficient to induce an animal to learn a shuttle-avoidance is more than a moderate, merely aversive stimulus, is well documented: defecation, urination, and other indicators of emotional upset are a correlate of shockavoidance conditioning in animals, and are present when barely motivating levels of electric shock are used (Wolfe, Cavanagh, \& Lubar, 1966).

This experiment was performed in an attempt to replicate an earlier report of air-blast acquisition (Ray, 1966) and to examine in greater detail the possibility that shuttle-avoidance is acquired in an all-ornone fashion.

Subjects

Forty-nine healthy, experimentally naive, male Sprague-Dawley rats were used. These rats, ranging in age from 60 days to 110 days at time of training, were randomly divided into two groups: group $I(N=28)$, trained with a CS-US interval of 11 sec., and group II $(N=21)$, trained with a CS-US interval of $8 \mathrm{sec}$. All rats were housed in community cages (approximately eight per cage) on an ad lib diet of Purina chow and water.

\section{Apparatus}

The apparatus was a shuttle-avoidance apparatus modified for effective presentation of a pressurized air US (30 lbs. per sq. in.). A description of the apparatus is available elsewhere (Ray, 1966). The CS consisted of a 65 decibel buzzer. A thermal time-delay relay accurately maintained the CS-US interval at either $8 \mathrm{sec}$. or $11 \mathrm{sec}$.

\section{Procedure}

A naive rat was placed in the apparatus for a $2-1 / 2$ min. familiarization period and training was begun immediately thereafter. The intertrial interval was of the same duration as the familiarization period. Trials were experimenter terminated when a rathad run sufficiently far into the opposite compartment to reach a sighting line 9 in. from the center of the apparatus. If an animal did not shuttle, the trial was terminated after a total duration of $100 \mathrm{sec}$.

No rat was trained more than threedays, one session per day. Maximum session length was decreased each day: 15 trials for the first session, 11 trials for session two, and 9 trials for session three. Thus, no rat experienced more than 35 trials-many more than most rats require to learn the response to the established performance criterion of five correct responses in six trials (Ray, 1966). The rat was removed from the apparatus upon completion of the appropriate number of trials, returned to its home cage, and placed again in the apparatus $24( \pm 2) \mathrm{hr}$. later, if necessary. Rats were trained only in the afternoon. An animal was retired either upon attaining the performance criterion or reaching the 35 trials-whichever occurred first. Results

Four rats did not reach criterion within the allotted 35 trials and are therefore excluded from the data.

Table 1.

Mean Trials to Criterion and Standard Deviation for Each Group

\begin{tabular}{lcc} 
& Mean (s.e.) & Standard Deviation (s.e.) \\
\hline $\begin{array}{l}\text { Group I } \\
N=26\end{array}$ & $10.42(1.63)$ & $8.33(1.67)$ \\
$\begin{array}{l}\text { Group II } \\
N=19\end{array}$ & $7.26(1.06)$ & $4.62(1.09)$ \\
$\begin{array}{l}\text { Total } \\
N=45\end{array}$ & $9.10(1.03)$ & $6.36(0.72)$ \\
\hline
\end{tabular}


The hypothesis that the CS-US interval significantly affected the rate of learning in this situation was tested and rejected $(p>0.25)$. The two training groups were therefore combined for the remainder of the analysis. Means and standard deviations are summarized in Table 1.

Fourteen rats ( 31 per cent) acquired the response in an all-or-none manner-criterion performance was preceded only by incorrect responses (e.g., EEEEEAAAAA), and there was no oscillatory sequence that culminated in the criterion run. Among these rats, two (4.4 percent) achieved criterion performance in one trial, five others (11 percent) in two trials. Mean trials to criterion for these 14 animals was 3.92 trials, with a standard deviation of 2.59 trials.

The remaining data were tested statistically for nonincrementality (stationarity or lack of oscillation) in the manner suggested by Theios \& Dunaway (1964). The trials between the first conditioned response (an avoidance) and the last failure (an escape) prior to criterion were divided in half, and the proportion of avoidance responses in each half determined. A t-ratio was then computed on the two distributions of proportions. The data were non-incremental (all-or-none) $(t=4.34$, $p<.01$ ); there were many fewer avoidance responses in the second half than in the first half of the oscillation sequence. Thus, the entire sample may be considered to have acquired the response in an all-or-none manner.

Fecal bolus counts were taken on all but seven rats. Thirteen rats (26 percent) did not defecate on the first day. The mean number of fecal boluses eliminated by those rats which did defecate on the first day was 2.2. By the second day, emotionality was the exception: six rats (12 percent) defecated.

\section{Discussion}

The number of trials required by the sample as a whole to learn the avoidance is low in comparison with shock avoidance experiments, confirming an earlier report of the efficacy of pressurized air in this situation (Ray, 1966). More importantly, mean learning rate approaches one-trial, in the literal sense, in those 14 rats which shifted abruptly from escape to avoidance responding.

Non-incrementality accompanies a drastic reduction in trials to criterion. Fewer Ss oscillate between correct and incorrect responses, once having successfully performed the avoidance: those Ss which oscillate do so only briefly. Thus shuttle-avoidance appears here as all-or-none learning.

Electric shock has sustained both rapid acquisition and non-incremental learning in one shuttle situation (Solomon \& Wynne, 1953). In this experiment, performed on dogs, the US was so intense as to nearly tetanize the animal. Even so, only three of 30 dogs learned in a non-statistical all-or-none manner. In the present experiment 14 of 45 rats, nearly one-third, learned in the same way. Moreover, on the basis of fecal bolus counts, a very moderate level of anxiety was in evidence in the pressurized air situation. Solomon and Wynne characterized their procectureas emotionally traumatic. Electric shock in any intensity less than traumatic has not sustained rapid learning in the shuttle-avoidance task, and in the two most complete parametric studies of electric-shock shuttle-avoidance (Brush, 1957; Wolfe et al, 1966), no mention of non-incremental learning is made: non-incremental acquisition has been observed only rarely in the electric-shock shuttle situation.

The view that shuttle-avoidance is learned gradually, though widely held (Atkinson etal, 1965), is not justified. Shuttle-avoidance is presumably difficult because the $S$ must re-enter the compartment where previously it had been painfully punished. If, on the other hand, punishment is mild, little conflict should arise; learning should show a corresponding increase in rate. It is likely that electric shock at motivational levels elicits emotional responses incompatible with learning. Wolfe et al (1966) observed that even $1.0 \mathrm{ma}$, while not motivating to all cats, induced emotionality in those which responded to it.

The present findings indicate, also, that the results reported by Theios \& Dunaway (1964) can be attributed to the fact that they used an electric shock US. Shuttleavoidance is not an inherently incremental process as they suggest. Moreover, it is not necessarily learned slowly, gradually, or with much oscillation, as stated by Atkinson et al (1965). Shuttle-avoidance can be learned in an all-or-none fashion and in one trial.

\section{References}

Atkinson, R. C., Bower, G. H., \& Crothers, E. J. An introduction to mathematical learning theory. New York: Wiley, 1965.

Baum, M. An automated apparatus for the avoidance training of rats. Psychol. Rep., 1965, 16, 1205-1211.

Brush, F. R. The effects of shock intensity on the acquisition and extinction of an avoidance response in dogs. J. comp. physiol. Psychol., 1957, 50, 547-552.

Ray, A. J. Jr. Shuttle-avoidance: rapid acquisition to pressurized air conditioned stimulus. Psychon. Sci., 1966, 5, 29-30.

Solomon, R. L., \& Wynne, L. C. Traumatic avoidance learning: acquisition in normal dogs. Psychol. Monogr., 1953, 67, No. 4 (Whole No. 354), 1-19.

Theios, J., \& Dunaway, J. E. One-way vs. shuttle avoidance conditioning. Psychon. Sci., 1964, 1, 251-252.

Wolfe, J., Cavanagh, A., \& Lubar, J. Avoidance behavior of the cat as a function of shock intensity and training schedule. Psychol. Rep., 1966, 18, 287-294.

\section{Noles}

1. Research conducted in the Department of Psychology, North Dakota State University, with support from NSF-Grant 1408.

2. Now at Carleton, University, Ottawa 1, Ontario, Canada. 